\title{
Inovação no polo de moda: uma análise da di- mensão marca nas micro e pequenas empresas da região Grande Florianópolis
}

\author{
Innovation in the fashion hub: an analysis of the size tag on \\ micro and small enterprises in the region Florianópolis
}

RESUMO

por Francieli Regina Balem e Luiz Salomão Ribas Gomez

Este artigo visa apresentar o resultado de uma análise sobre o critério marca, decorrente da coleta de informações do projeto Agente Local de Inovação - aplicado em parceria do Serviço Brasileiro de Apoio as Micro e Pequenas Empresas e o Conselho Nacional de Desenvolvimento Científico e Tecnológico. 0 estudo foi realizado em vinte e duas MPEs (micro e pequenas empresas) do polo de Moda da Grande Florianópolis. A partir de estudos sobre inovação, marca, branding, propriedade intelectual, e os dados obtidos na coleta de informações, objetiva-se com essa pesquisa analisar as marcas que possuem registro e como utilizam de sua marca para ganhar competitividade no mercado. Uma vez que, o reconhecimento de uma marca requer um trabalho efetivo. A pesquisa realizada junto as vinte e duas participantes dos processos que ocorreram nas empresas corroborou a percepção inicial de que, para a maioria das empresas, obter o registro da marca é importante, e usufruir disso de uma maneira consistente para obter melhor resultados é um grande desafio.

Palavras-chave: Inovação, marca, moda.

\section{ABSTRACT}

This article presents the results of an analysis of the test mark, due to the collection of information design Innovation Agent Local - delivered in partnership the Brazilian Support Service for Micro and Small Enterprises and the National Council for Scientific and Technological Development. The study was conducted in twenty-two MSEs Polo Fashion Florianópolis. From studies on innovation, brand, branding, intellectual property, and the data obtained in gathering information, the objective of this research to examine the marks that are registered and how to use your brand to gain market competitiveness. The recognition of a brand requires an effective job, the survey among the twenty-two participants of the processes that occurred in the companies confirmed the initial perception that, for most companies, obtaining trademark registration is important, and make use of it a consistent way to get better results is a challenge.

Keywords: innovation, brand, fashion. 

pequenas empresas da região Grande Florianópolis.

\section{INTRODUÇÃO}

É sabido que, dada a dinâmica atual do contexto social e econômico, inovar, é de fundamental importância para um empreendimento manter-se e crescer no mercado, independente do ramo em que atua. "As empresas inovadoras são as que tornam a inovação uma atividade sistêmica, concentrando-se em suas competências essenciais" (KOLOPOULOS, 2011, p.65). É por meio da inovação que a organização quebra barreiras, muda estruturas, diferencia-se e cresce com competitividade.

A inovação abrange uma gama de atributos empresarias, dentre eles, elaborar a gestão inteligente da marca, focando estratégias que visam à valorização de bens tangíveis $\mathrm{e}$ intangíveis, de modo que a qualidade percebida e o valor patrimonial dessa, seja reconhecida pelo público-alvo. A marca reconhecida carrega com ela valores emocionais de experiências vividas pelo seu público-alvo que as tornam exclusivas.

A marca é a soma intangível dos atributos de um produto; seu nome; embalagem e preço; sua história; reputação e maneira como ele é promovido. A marca é também definida pelas impressões dos consumidores sobre as pessoas que a usam; assim como pela sua própria experiência pessoal (OGLIVY, 2001).

Por isso "uma marca se comunica com os consumidores no nível dos sentidos e das emoções; uma marca se aviva para as pessoas, forjando uma conexão profunda e duradoura" (GOBÉ, 2002; p. 19).

Neste sentido da marca como fator de significação cultural e individual, "o que se vende já não é um produto, mas uma visão, um 'conceito', um estilo de vida associado à marca" (LIPOVETSKY, 2007; p. 40), que vai permitir aos indivíduos expressarem suas próprias individualidades e visões de mundo, que têm no novo e na mudança um prazer mundano: "nome, logotipo, design, slogan, patrocínio, loja, tudo deve ser mobilizado, redefinido, dotado de um novo visual, com vista a renovar o perfil de imagem, a dar uma alma ou um estilo à marca".

0 objetivo desde artigo é compreender o estado atual da dimensão marca, das empresas da cadeia produtiva de moda (confecção, joias e acessórios) da região da Grande Florianópolis. Para tanto, a metodologia utilizada será o diagnóstico - Radar da Inovação nas Micro e Pequenas Empresas - desenvolvida por Bachmann a Associados, de uso exclusivo do SEBRAE - serviço de atendimento as micro e pequenas empresas - com uma abordagem quantitativa, aplicado com os empresários e stakolders, de pesquisas nos sítios das empresa na web, para levantar e analisar os recursos e ações que têm direcionado as principais estratégias de inovação referente a abordagem "Marca".

0 objetivo desde artigo é compreender o estado atual da dimensão marca, das empresas da cadeia produtiva de moda (confecção, joias e acessórios) da região da Grande Florianópolis. Para tanto, a metodologia utilizada será o diagnóstico - Radar da Inovação nas Micro e Pequenas Empresas - desenvolvida por Bachmann đ̇ Associados, de uso exclusivo do SEBRAE - serviço de atendimento as micro e pequenas empresas - com uma abordagem quantitativa, aplicado com os empresários e stakolders, de pesquisas nos sítios das empresa na web, para levantar e analisar os recursos e ações que têm 


\section{Inovação no polo de moda: uma análise da dimensão marca nas micro e pequenas empresas da região Grande Florianópolis.}

direcionado as principais estratégias de inovação referente a abordagem "Marca".

\section{Inovação}

A inovação é uma questão emergente e essencial no novo cenário que se apresentam os negócios. Koulopoulos (2011) define o conceito de inovação como algo diferente de invenção, afirma que inovação não é invenção, ela não visa criar a próxima bugiganga, uma droga maravilhosa nem uma arma de destruição em massa. A inovação não objetiva acelerar a velocidade com que criamos objetos, mas agilizar o modo como criamos valor.

0 Manual de 0slo (OECD,2005,p.46) apresenta o conceito de inovação da seguinte forma:

\footnotetext{
“Uma inovação é a implementação de um produto (bem ou serviço) novo ou significativamente melhorado, ou um processo, ou um novo método de marketing, ou um novo método organizacional nas praticas de negócios, na organização do local de trabalho ou nas relações externas".
}

0 conceito de inovação muitas vezes é associado com a ideia de que ela seja algo novo, mas ao se estudar autores que tratam do assunto, percebe-se que é algo muito mais além. Kolopoulos (2011) afirma que inovação é o resultado de um processo sustentado de incontáveis repetições, que visam refinar o produto e adequá-lo as necessidades do mercado. Já para Porto (2010), a inovação está associada a uma gama de conhecimento que são arranjados em uma dada configuração e não somente a uma tecnologia ou mercado, ou seja, ela é uma nova maneira de utilizarmos conhecimentos e ferramentas já existentes.

Dentro deste conceito, Tidd (2008) nos apresenta uma classificação para inovação onde ela é dividida em 4 tipos:

1) Inovação de produto: mudanças em produtos/serviços que uma empresa oferece; 2) Inovação de processo: mudanças na forma em que os produtos/serviços são criados e entregues; 3) Inovação de posição: mudanças no contexto em que produtos/ serviços são introduzidos; 4) Inovação de paradigma: mudanças nos modelos mentais subjacentes que orientam o que a empresa faz.

A partir desta conceituação, percebe-se que o processo de inovação diz respeito à utilização de diversas iniciativas que resultarão em mudanças importantes criando novas experiências. Nessa dinâmica e forte influencia da experiência do consumidor, Gallo (2011) diz que, a inovação não se encaixa facilmente num pacote único, criado, projetado e montado por um único individuo.

As novas ideias raramente são comercializadas sem uma equipe inspirada de entusiastas criativos e apaixonados, que transformaram essas ideias em realidade. Sua concepção dá-se quando há uma significativa mudança de comportamento. De uma maneira 

pequenas empresas da região Grande Florianópolis.

geral, a inovação visa transformar o contexto ao seu redor criando possibilidades que antes não seriam imaginadas (KOULOPOULOS, 2011).

Essas possibilidades de inovação, como conceituadas por alguns autores, está diretamente ligada aos processos inovativos, os quais proporcionam a competitividade das empresas. Para Prahalad e Krishnan (2008) as empresas precisam basear-se em soluções e experiências inovadoras, e construir modelos específicos para concentrar-se no consumidor. As empresas inovadoras são as que tornam a inovação uma atividade sistêmica, concentrando-se em suas competências essenciais (Koulopoulos, 2011), e os processos internos são fundamentais para apoiar a cultura de inovação (PRAHALAD E KRISHNAN, 2008).

Nessa dinâmica atual Prahalad e Krishnan (2008) afirmam que o valor esta migrando de produtos e serviços para soluções e experiências. Na mesma linha de pensamento, Koulopoulos (2011) ressalta que o valor e, por associação, a inovação residem inteiramente na experiência do cliente. Essa experiência que é mencionada, esta diretamente relacionada com o que marca de uma empresa é capaz de oferecer de diferencial aos seus consumidores.

\section{Marca}

A palavra marca vem originalmente de brandr, ou seja, para queimar e, a partir dessas origens fez seu caminho em anglo-saxão. Foi, naturalmente, pela queima que o homem primitivo estampava em seu gado, e com o desenvolvimento de compradores seria usar essas marcas como um meio de distinguir entre o gado de um fazendeiro e outro. Assim, a utilidade de marcas, como um guia para a escolha foi estabelecido, um papel que se manteve inalterado para os dias de hoje. (BLACKETT, 2004).

No Oxford American Dictionary (1980) contém a seguinte definição: Marca (substantivo): uma marca, produtos de um determinado fazer: uma marca de identificação feita com um ferro quente, o ferro usada para isto: um pedaço de queima ou queimada madeira, (verbo): marcar com um ferro quente, ou a etiqueta com uma marca. (BLACKETT 2004).

Batey (2010) indica a origem das marcas em três continentes: 1- a origem africana, porque os oleiros do antigo Egito colocavam os símbolos nos tijolos para identificá-los; 2- a origem europeia, porque os primeiros sinais de marcas de origem comercial por causa da exigência das guildas medievais para que os artesãos marcassem seus produtos, distinguindo-os das imitações de qualidade inferior; 3- a origem norte-americana, porque os rancheiros marcavam o gado para identificá-los.

Desde o principio o uso da palavra marca, já veio com uma significância importante. De identificar algo, com a evolução da indústria, e o surgimento de várias empresas, o homem teve a necessidade de identificar os seus produtos e diferenciá-los dos outros através da marca. Entretanto, a marcas atualmente não identificam apenas empresas, também identificam instituições, religiões, partidos políticos, equipes de futebol, e até pessoas.

Atualmente as marcas são muito mais do que símbolos marcados nos produtos para 


\section{Inovação no polo de moda: uma análise da dimensão marca nas micro e pequenas empresas da região Grande Florianópolis.}

identificar o seu produtor, garantindo procedência e qualidade. Segundo Keller e Machado (2006; p. 36) a força de uma marca está "no que os clientes aprenderam, sentiram, viram e ouviram sobre ela como resultado de suas experiências ao longo do tempo".

Assim, Cardoso (2009) explica que muito além de uma simples representação gráfica, a marca passa a ser, tudo aquilo que representa uma empresa, e que quando visto ou sentido é logo associado à empresa, desde uma simples cor, um traço, uma música uma personagem até um cheiro. De acordo com o valor de cada marca ela possui mais elementos a que the são associados.

A marca converteu-se num fenômeno do nosso tempo de tal forma significativo que é quase impossível exprimir quaisquer conceitos, ou mesmo delinear personalidades, sem lhes colocar-mos uma marca. (OLINS, 2005; p. 26)

Batey (2010) exemplifica definições de marca da seguinte maneira: você compra um produto pelo que ele faz; você escolhe uma marca pelo que ela significa. Um produto pode ficar ultrapassado rapidamente; uma marca é eterna. Um produto pode ser copiado por um competidor; uma marca é única.

Sendo assim, Cardoso (2009) a marca de uma empresa, serviço ou produto, é tudo o que pretende marcar a imagem na mente do consumidor, e faz com que ele associe a imagem à qualidade do produto. A marca é mais intangível do que tangível, pois o consumidor tem sensações, experiências e percepções diferentes sobre uma mesma marca em relação a outro consumidor semelhante a ele. Este novo enfoque pode ser reforçado por Nunes (2003, p.17), ao afirmar que “[...] marcas são entidades constituídas essencialmente por aspectos intangíveis de percepção e valor que habitam a mente e o coração do usuário, do cliente, do consumidor final."

\section{Propriedade industrial: registro de marca}

A marca permite que o consumidor associe qualidades aos produtos e serviços identificados por ela. Para que isso ocorra, considera-se a utilização de proteção da propriedade industrial da mesma.

A Lei de Propriedade Industrial permite que uma pessoa ou uma empresa obtenha a propriedade de uma marca a fim de evitar a presença, no mercado, de marcas idênticas ou semelhantes que possam confundir o consumidor quanto à origem de um produto ou serviço. A propriedade da marca deve ser solicitada ao INPI, responsável por emitir, no Brasil, os certificados de registro. A marca registrada de uma empresa pode evitar a confusão do consumidor e a concorrência desleal pela semelhança ou imitação (JUNGMANN 2010, p. 57).

\footnotetext{
“1. Proteja a sua marca. A lei de marcas oferece a provisão para a proteção de sua
} marca e nome corporativo, seu logotipo e cores, a forma da sua embalagem, chei- 

pequenas empresas da região Grande Florianópolis.

ros, e o jingle publicitário que for usar. Esta proteção pode durar indefinidamente, sujeito a pagamento de uma taxa e à observação de algumas regras onerosas de uso. A lei de patentes permite proteger produto por períodos de até 20 anos, desde que o produto é a sua invenção, e é uma idéia nova ou não-óbvio". (BLACKETT, 2004 p. 9).

A organização mundial de propriedade intelectual, OMPI (2003) afirma que o registro, segundo a legislação sobre marcas aplicável, dá à sua empresa o direito exclusive de impedir que terceiros comercializem produtos idênticos ou semelhantes com uma marca igual ou tão semelhante que possa causar confusão entre os consumidores.

Ainda Jungmann (2010) explica que, o titular da marca tem o direito de defender 0 registro e zelar pela integridade material e pela reputação da marca. A reprodução não autorizada da marca pode ser combatida por meio de ações judiciais. Ele também pode autorizar outras pessoas a utilizar a marca por meio de contratos de licença de uso, averbando-os no INPI. Pode ainda, transferir a titularidade do registro ou do pedido para outra pessoa, e essa cessão deve ser anotada pelo INPI no certificado de registro e no próprio pedido, conforme o caso. 0 titular não pode impedir que comerciantes ou distribuidores utilizem suas próprias marcas juntamente com a marca do produto ou serviço, na sua promoção e comercialização, bem como não pode impedir que fabricantes de acessórios utilizem a marca para indicar a destinação do produto. Ele também não tem o direito de impedir a citação da marca em discurso, obra científica ou literária ou qualquer outra publicação, desde que sem conotação comercial e sem prejuízo para seu caráter distintivo.

A função principal da marca é facilitar ao consumidor a identificação de um produto (bem ou serviço) de uma empresa específica, para que ele possa diferenciá-lo de outros produtos idênticos ou semelhantes da concorrência. Consumidores satisfeitos com um determinado produto tendem a voltar a comprá-lo ou a usá-lo. Para que isso seja possível, é necessário que eles sejam capazes de diferenciar produtos idênticos ou semelhantes.

Para a Oganização Mundial de propriedade intelectual - OMPI (2003) as marcas:

- possibilitam que os consumidores diferenciem produtos semelhantes;

- permitem que as empresas destaquem seus produtos;

- são importantes para a comercialização e a base para o estabelecimento da imagem e reputação de uma linha no mercado;

- são licenciadas e fornecem uma fonte direta de renda através dos "royalties";

- são um elemento fundamental nos acordos de franquia;

- podem ser um ativo comercial de valor;

- incentivam os empresários a investirem na manutenção ou no aprimoramento da qualidade dos seus produtos;

- podem ser úteis para a obtenção de financiamentos. 

pequenas empresas da região Grande Florianópolis.

0 valor para as empresas de possuir marcas fortes é incontestável. Marcas que mantêm a sua promessa de atrair compradores fiéis que irão retornar a eles em intervalos regulares. 0 benefício para o proprietário da marca é que previsão de fluxos de caixa torna-se mais fácil, e torna-se possível planejar e gerenciar o desenvolvimento do negócio com maior confiança. Assim, as marcas, com sua capacidade de garantir renda, podem ser classificados como bens de produção exatamente da mesma forma que quaisquer outros, bem como os ativos mais tradicionais de uma empresa como as instalações, equipamentos, dinheiro, investimentos e assim por diante. (BLACKETT (2004).

Para o OMPI (2003) Uma marca bem selecionada e desenvolvida é um ativo de valor para a maioria das empresas. Para algumas delas pode até ser o ativo mais valioso. Isto ocorre porque os consumidores associam o símbolo a uma reputação, imagem e conjunto de qualidades que eles valorizam, e estão dispostos a pagar mais por um produto que leve esta marca. Por isso, o simples fato de possuir uma marca com boa imagem e reputação no mercado já coloca a empresa em posição vantajosa com relação à concorrência.

Mozota (2011) entende que a marca ultrapassa as delimitações de um nome, "Uma marca é um conjunto de associações vinculadas a um nome, sinal ou símbolo, relacionado a um produto ou serviço". Além dos atributos identificáveis nos símbolos gráficos, a criação e a gestão de uma marca requerem o desenvolvimento de afetos e ideias positivas, nos diversos pontos de contato entre o público consumidor e as expressões relacionadas à marca. As manifestações e atuações tangíveis dos produtos, dos serviços e da publicidade em geral, de acordo com o grau de satisfação proporcionado, promovem o desenvolvimento de um conjunto de valores subjetivos. Esses valores intangiveis são associados e passam a ser representados pelas expressões oficiais da marca, como logotipo, símbolo, características das embalagens e outros.

Sendo assim, a marca "focaliza o aspecto mais forte do caráter humano; o desejo de transcender a satisfação material e experimentar a realização emocional. A marca é univocadamente estabelecida para cumprir essa tarefa" (GOBÉ, 2002; p. 19), incentivando a criação de significado emocional pelo consumidor. "Embora a natureza desses significados evolua com o tempo, uma marca vai continuar sendo um agrupamento de significados. Aliás, esses significados precisam ser constantemente renovados, modificados, polidos, e, quando necessário, trocados". (BATEY, 2010; p. 31). Fazer isso é, então, a função de branding, ou gestão de marcas.

\section{Branding: gestão da marca}

Branding é um termo inglês, que serve para descrever todas as ações relacionadas aos projetos de criação e gestão de marcas. Quando se fala numa ação de branding, entende-se que a marca será apreciada como um todo - conjunto - nome, desenho, posicionamento, e comunicação.

0 branding representa atualmente uma ferramenta muito importante na valorização de uma marca, assim, as ações de Branding envolvem diversas áreas, como administração, 

pequenas empresas da região Grande Florianópolis.

marketing, publicidade e design. Para Martins (2006), branding é o conjunto de ações ligadas à administração das marcas. São ações que, tomadas com conhecimento e competência, levam as marcas além da sua natureza econômica, passando a fazer parte da cultura, e influenciar a vida das pessoas. Ações com a capacidade de simplificar e enriquecer nossas vidas num mundo cada vez mais confuso e complexo.

Branding é a implementação de um planejamento de mercado que organiza as ações estratégicas para a construção e a projeção da marca no mercado. Os autores Kottler e Keller (2006), afirmam que branding significa dotar produtos e serviços com o poder de uma marca. Complementam ainda, que o branding diz respeito a criar estruturas mentais e ajudar o consumidor a organizar seu conhecimento sobre produtos e serviços, de forma que torne sua tomada de decisão mais esclarecida e, nesse processo, gere valor a empresa.

Cardoso e Perassi (2011) explicam que o objetivo do branding é criar estruturas mentais e ajudar o consumidor a organizar seu conhecimento sobre produtos ou serviços, de forma que torne sua decisão mais esclarecida. Com isso, torna-se fundamental esclarecer ao consumidor a diferença entre marca e produtos ou serviços. Pois, com uma marca forte e bem posicionada, considera-se que os clientes tenham uma boa aceitação dos produtos e serviços, pela experiência positiva que lhes é proporcionada pela marca.

Considera-se que o branding foca em colocar a marca de uma empresa na mente do consumidor, transmitindo assim sensações e causando emoção a esse, assim como 0 Lindstrom (2007) defende que para potencializar a relação de interação entre cliente/ marca a nova geração de branding cria marcas multissensoriais capazes de estimular os sentidos humanos. "Como seres humanos, alcançamos o máximo de nossa eficiência e receptividade quando operamos usando os cinco sentidos", segundo Lindstrom (2007, p. 25). Essas sensações transmitidas garantem a fidelidade e a confiança necessária para que a marca posicione-se como top of mind do consumidor.

Nesse sentido, as estratégias de Branding como uma atividade interdisciplinar, vem sendo disseminado e implantado pelos designers em todos os processos de construção de identidade de um produto, marca ou serviço.

Apoiado em conceitos mais amplos, como o de DNA de marca, e por informações obtidas de outros profissionais como os de publicidade, administração e os de marketing, fica com evidente que se trabalhar em uma marca é possível construir um conceito comercial afetivo com os consumidores. Consumidores que reconhecem uma marca por meio da aproximação que a mesma proporciona com os valores emocionais de experiências vividas, tem mais facilidade de se tornarem preferencias na hora da escolha e até mesmo exclusivas.

\section{Procedimentos Metodológicos}

Este artigo é uma pesquisa exploratória realizada a partir de uma revisão bibliográfica condizentes com o temas como: inovação, marca, propriedade industrial, registro de marca e branding. Referencias bibliográficas elaborada com embasamento em materiais 

pequenas empresas da região Grande Florianópolis.

já publicados principalmente por artigos e livros científicos (GIL, 2002). Inicialmente foi realizada uma pesquisa bibliográfica para explorar os conceitos relacionados ao tema, que segundo Mattar (2001) é uma das formas mais rápidas e eficazes de aprofundar um problema de pesquisa, pois utiliza trabalhos já existentes.

Em seguida foi realizado um estudo qualitativo, com observação participante, onde, segundo Roesch (1999), os dados são obtidos por meio do contato direto do pesquisador com o fenômeno observado e coleta de informações no local natural onde os fatos e fenômenos acontecem (SOUZA; FIALHO; OTANI, 2007) e proporcionam a compreensão profunda do fenômeno social, através de uma análise da situação mais complexa de acordo com suas particularidades (RICHARDSON, 1985).

0 presente estudo foi efetuado em analises de MPEs do pólo de Moda (confecção acessórios e joias), atendidas pelo Projeto ALI - Agente Local de inovação - no período de novembro de 2011 a julho de 2012, na região da Grande Florianópolis, que abrangeu cidades como Florianópolis, Palhoça, São José, Biguaçu e Caropaba, em Santa Catarina.

Para coleta e análise dos dados foi utilizado uma metodologia desenvolvida por Bachmann e Destefani (2008) aplicado pelo Sistema Brasileiro de Apoio de Micro e Pequenas Empresas - SEBRAE. Este trabalho apresenta a análise da Dimensões do Gráfico Radar da Inovação, Marca, que para os autores, no estudo, Marca é entendida como o conjunto de símbolos, palavras (slogan) ou formatos pelos quais uma empresa transmite sua imagem, ou promessa, aos clientes. A inovação nesta dimensão implica, por exemplo, em tirar partido da marca para alavancar outras oportunidades de negócio ou, inversamente, usar outros negócios para valorizar a marca. Para avaliar esta dimensão, considerou-se as questões:

1. A empresa tem uma ou mais marcas registradas?

2. A marca não é registrada?

3. A empresa não tem marca?

4. A empresa fez um novo uso de sua marca (em outro tipo de produto ou negócio)?

As questão estão dispostas no método de Bachmann e Destefani (2008) e serviram de apoio para o resultado da pesquisa.

\section{Resultados da Pesquisa}

A história de Santa Catarina na área da moda não é recente, algumas cidades já são consideradas como "Berço da Fiação Catarinense" desde o início da década de 1990 (CORRÊIA E PIMENTA, 2006). Contudo, ao mesmo tempo em que diversos analistas nacionais e internacionais revelam o poder criador das indústrias têxteis, Santa Catarina ainda é considerada meramente produtora de moda/confecção. De acordo com Locks et al. (2009), Santa Catarina tem a capacidade de oferecer ao mundo, de maneira eficiente em termos de criatividade, uma moda ligada ao lifestyle brasileiro, pelo qual o mercado 
Inovação no polo de moda: uma análise da dimensão marca nas micro e pequenas empresas da região Grande Florianópolis.

mundial estará interessado.

Tratando especificamente do mercado de Santa Catarina e de suas MPEs, pode-se dizer que há um notável diferencial no que tange a qualidade técnica, têxtil e criativa. Entretanto, a premissa de que tem se algo muito importante para se destacar no mercado - a marca- ainda não cogita na mente dos empresários.

Diante destes indicativos, apresenta-se uma breve descrição das 22 empresas que são objetos de estudo dessa pesquisa.

Tabela 01: Segmentação das empresas

\begin{tabular}{|l|l|l|}
\hline \multicolumn{1}{|c|}{ Empresa } & \multicolumn{1}{c|}{ Segmento/Estilo } \\
\hline A & Acessórios & Semi-joias \\
\hline B & Acessórios & Bijuterias \\
\hline C & Acessórios & Bijuterias \\
\hline D & Acessórios & Bijuterias \\
\hline E & Acessórios & Calçados sob medida \\
\hline F & Acessórios & Bolsa de Couro \\
\hline G & Confecções & Lingeries- homewear \\
\hline H & Confecções & Lingeries/ Pijamas \\
\hline I & Confecções & Fitness \\
\hline J & Confecções & Biquini/ Lingerie/ Fitness \\
\hline K & Confecções & Uniformes \\
\hline L & Confecções & Feminina- casual/ night wear \\
\hline M & Confecções & Feminina- Night wear \\
\hline N & Confecções & Feminina- casual/ night wear \\
\hline O & Confecções & Feminina- ecomoda \\
\hline P & Confecções & Feminina- facção \\
\hline Q & Confecções & Moda Unissex- surf wear \\
\hline R & Confecções & Unissex \\
\hline S & Confecções & Unissex \\
\hline T & Confecções & Unissex- Camisetas \\
\hline U & Confecções & Unissex- Camisetas \\
\hline V & Confecções & Decorativa \\
\hline & & \\
\hline
\end{tabular}

(Fonte: Autores)

De forma geral, na Tabela 1 é possível observar que há uma variedade de segmentos e estilos, que abrangem: acessórios, calçados, bolsa de couro, facção, biquínis, lingeries, moda sustentável, fitness entre outros.

As empresas possuem um estilo, um segmento definido, porém, a Figura 01, demonstra um panorama de qual estado esta a questão da marca, das 22 empresas estudadas toda 
Inovação no polo de moda: uma análise da dimensão marca nas micro e pequenas empresas da região Grande Florianópolis.

elas possuem uma marca para identificar seus produtos/serviços. Referente ao registro, 14 empresas já possuem a marca registrada ou a solicitação da mesma junto ao órgão responsável - INPI, isso representa $63,33 \%$. As que não possuem registro são 8 empresas que representam $36,33 \%$.

\section{Proteção de Marca}

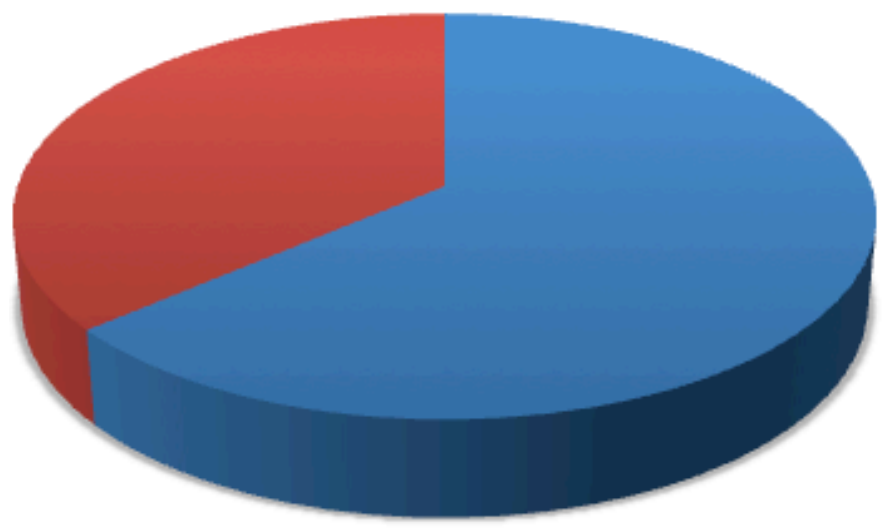

- A empresa tem uma ou mai marcas registradas.

- A marca da empresa não é registrada.

A empresa não tem marca.

Figura 1- Proteção da marca (fonte: autores)

Referente a alavancagem da marca, que condiz acerca de onde a empresa utilizada a sua marca como esta explicito na Figura 02, são 8 empresas usam sua marca em outros tipos de produtos ou negócios, isso representa $36 \%$. As empresas que usam sua marca exclusivamente em seus produtos somam 13, que correspondem a $61 \%$. E apenas 1 empresa não utiliza sua marca na divulgação de seu produto, a qual corresponde a $2 \%$.

\section{Alavancagem da marca}

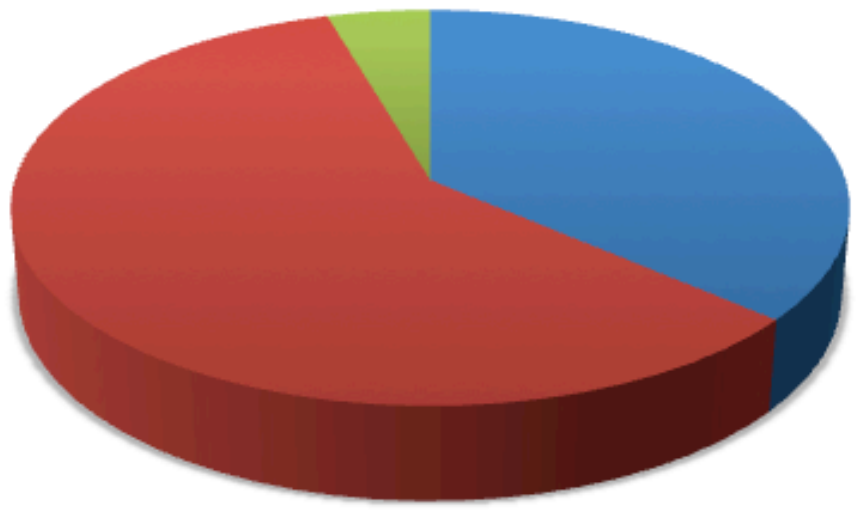

- A empresa usa sua marca em outros tipos de produtos e negócios.

- A empresa usa sua marca exclusivamente em seus produtos

- A empresa não usa sua marca nos produtos ou negócios.

Figura 2- Alavancagem da marca (fonte: autores) 

pequenas empresas da região Grande Florianópolis.

As informações acima apresentadas acerca do contexto em que encontra-se a questão referente a marca, denotam que, há controvérsias ainda da realidade versus a literatura atual. Corroborando estas indicações, é relevante citar o potencial apresentado por essas empresas, principalmente por meio de suas marcas presentes na região. Marcas, entretanto, que ainda lidam com carência de investimentos. A potencialização e otimização do setor poderá fazer com que Santa Catarina efetivamente se torne um polo evidente, capaz de expor grandes marcas, tanto para a moda brasileira, quanto para o mercado internacional.

\section{Considerações Finais}

0 processo de construção de uma marca, quando bem planejado, prevê atitudes de serviço, de qualificação de produtos e de comunicação pública ou publicitária, as quais promovem positivamente a construção da imagem da marca nas mentes dos fornecedores, dos consumidores e do público em geral. A conjugação coerente e eficiente entre o registro de uma marca, promove o valor da marca, direito de exclusividade de uso, e ainda potencializando-a no mercado.

Ressalva-se que o programa de apoio aos micros e pequenos empreendedores do governo com entidades promovedoras de inovação, sendo o Programa ALI - Agente Local de Inovação, desenvolvido e implantado pelo Serviço Brasileiro de Apoio as Micro e Pequenas Empresas SEBRAE, vem oportunizar os valores e as finalidades de uma mar$\mathrm{Ca}$, promovendo sua visibilidade no mercado.

Nas empresas que representam 63,33\% que registraram sua marca junto ao órgão INPI, é notório que há uma preocupação, em relação a questão do uso da mesma, com tem benefícios a curto, médio e longo prazo, o que contribui para a permanência no mercado cada vez mais competitivo. Já nas 33,33\% que não possuem o registro, de fato existe um interesse em registrar a marca, por parte dos gestores, mas não existem iniciativas.

Com relação a alavancagem da marca, 61\% utilizam sua marca em outros tipos de negócios ou produtos, esse dado é bastante significativo, uma vez que, a marca passa a se tornar um meio de comunicação além do cotidiano de muitas empresas, o que gera consequentemente a imagem de uma marca na mente dos consumidores.

Diante do exposto, considera-se como indicativo de competitividade, as empresas usar de um registro eficiente para sua marca organizacional. Entretanto, considera-se, principalmente, que o processo, em si mesmo, apresenta-se como elemento um tanto quanto falho, onde uma marca é capaz de oferecer uma experiência gratificante e marcante aos consumidores, reforçando o processo de identificação entre consumidor e seu produto, algumas marcas ainda ficam na retaguarda.

Espera-se que, com o projeto em execução, e as ações sugeridas de melhoria, as marcas que não possuem um registro, façam-o, e além do registro, o qual é de fundamental importância, utilizem da marca como um fator decisivo na hora do consumidor decidir entre uma empresa e outra. Cabe aqui, para um estudo futuro, reavaliar essa 
Inovação no polo de moda: uma análise da dimensão marca nas micro e pequenas empresas da região Grande Florianópolis.

questão e gerar dados para verificar se ouve progresso no decorrer do projeto. 
Inovação no polo de moda: uma análise da dimensão marca nas micro e pequenas empresas da região Grande Florianópolis.

\section{Referências Bibliográficas}

> BACHMANN, D., DESTEFANI, H. Metodologia para Estimar o Grau de Inovação nas MPE: Cultura do Empreendedorismo e Inovação. Curitiba: 2008

> BATEY, M. 0 significado da marca: como as marcas ganham vida na mente dos consumidores. Rio de Janeiro: Best Business, 2010.

$>$ BLACKETT, Tom. What is a brand? A chapter from brands and branding an economist book. New York : Interbrand, 2004.

> CARDOSO, H. Aplicação de uma metodologia de branding no reposicionamento da marca de uma empresa de transportes aéreos. Desenhando o futuro: 2011.

$>$

H; PERASSI, R. A abordagem brand dna process, como fator motivacional na configuração da identidade e na gestão da marca. Trabalho apresentado para defesa co curso de especializaçãoo, UFSC: 2011.

$>$ CORRÊA, M. K.; PIMENTA, M. C. A. Reestruturação produtiva na indústria do vestuário no município de Brusque - SC. Revista Discente Expressões Geográficas, n. 2, p. 84-98, 2006.

$>$ GALLO, Carmine. A Arte de Steve Jobs: Princípios Revolucionários sobre Inovação para o Sucesso em Qualquer Atividade. São Paulo: Lua de Papel, 2010. 237 p.

$>$ GIL, Antonio Carlos. Como elaborar projetos de pesquisa. 4. ed. São Paulo: Atlas, 2002.

> JUNGMANN, Diana de Mello. Inovação e propriedade intelectual: guia para o docente / Diana de Mello Jungmann, Esther Aquemi Bonetti. - Brasília: SENAI, 2010.

$>$ KELLER, Kevin Lane; MACHADO, Marcos. Cestão Estratégica de Marcas. São Paulo: Pearson Prentice Hall do Brasil, 2006.

$>$ KOULOPOULOS, Thomas. Inovação com resultado: o olhar além do óbvio. São Paulo: Editora Gente/Editora Senac. 2011

> KOTLER P, KELLER, K L. 2006. Administração de marketing. São Paulo: Pearson Prentice Hall.

> LOCKS, E. B. D.; Martignago, G.; Evangelista, S.; Palumbo, S.; Serra, F. A. R. DELPHI: 0 Futuro da Moda de Santa Catarina - Previsões entre 2008 e 2012. Disponível e,: <http:// www.globadvantage.ipleiria.pt/wp-content/uploads/2009/10/working_paper-43_globadvantage.pdf $>$. Acesso em: 07 fev de 2011.

> LINDSTROM, Martin. Brandesense: a marca multissensorial. Porto Alegre: Bookman, 2007.

> MARTINS, José Roberto. Branding: Um manual para você criar, gerenciar e avaliar marcas. São Paulo: Global Brands, 2006. 312 p. 
Inovação no polo de moda: uma análise da dimensão marca nas micro e pequenas empresas da região Grande Florianópolis.

> MATTAR, F. Pesquisa de Marketing. 3š ed, São Paulo: Atlas, 2001.

> MOZOTA, Brigitte Borja de. Cestão do design: usando o design para construir valor de marca e inovação corporativa. Porto Alegre: Bookman, 2011.

> OGLIVY, David. Confissões de um Publicitário. São Paulo: Bertrand Brasil, 2001. 217 p.

$>$ OECD. Oslo Manual: guidelines for collecting and interpreting innovation data, 3 rd ed., 2005.

> OMPI. Organizacao mundial da propriedade Intelectual. A criação de uma marca: Uma Introdução às Marcas de Fábrica ou de Comércio para as Pequenas e Médias Empresas. Organizacao mundial da propriedade Intelectual. Suiça: 2003

> OLINS, Wally. A Marca. Lisboa: Verbo, 2005.

$>$ GIL, Antonio Carlos. Como elaborar projetos de pesquisa. 4. ed. São Paulo: Atlas, 2002.

> GOBÉ, Marc. A Emoção das Marcas. Rio de Janeiro: Campus, 2002.

> LIPOVETSKY, Gilles. A Felicidade Paradoxal: Ensaio dobre a sociedade de hiperconsumo. Lisboa: Edições 70, 2007.

$>$ PRAHALAD, C.K. KRISHMAN, M.S. A nova era da inovação: impulsionando a co-criação de valor ao longo as redes globais. Rio de janeiro: Elsevier, 2008.

$>$ PORTO, Renata; BROD JUNIOR, Marcos. Processos de Inovação no Design de Produtos. In: CONGRESSO BRASILEIRO DE PESQUISA E DESENVOLVIMENTO EM DESIGN, 9., 2010, São Paulo. Anais gć Congresso Brasileiro de Pesquisa e Desenvolvimento em Design. São Paulo: Anhembi Morumbi, 2010. v. 9, p. 3697 - 3705. Disponível em: 〈http://blogs. anhembi.br/congressodesign/anais/anais/>. Acesso em: 30 mar. 2012.

> RICHARSON, Roberto J. Pesquisa Social: métodos e técnicas. São Paulo: Atlas, 1989.

> SOUZA, Antonio Carlos de; FIALHO, Francisco Antonio Pereira; OTANI, Nilo. TCC: métodos e técnicas. Florianopolis: Visual Books, 2007.

> TIDD, Joe. Gestão da Inovação. Porto Alegre: Bookman, 2008. 
Inovação no polo de moda: uma análise da dimensão marca nas micro e pequenas empresas da região Grande Florianópolis.

Francieli Regina Balem, Designer Industrial, especialista em gestão de design, mestranda em Gestão de design com foco em inovação.

francielibalem@gmail.com 